\title{
Changes in Liquidity Associated with Removal of Companies from the FTSE 100 Index.
}

\author{
Ahmed Aboud \\ Malin Karlsen \\ Faculty of Business and Law, University of Portsmouth, UK
}

\begin{abstract}
This study investigates changes in liquidity associated with removal of companies from the FTSE 100 index during the time period 2008-2016. Using an event study methodology, we document significant negative abnormal returns that are more negative in the period prior to removal and a significant decrease in trading volume once a company is removed from the index. Moreover, regression analysis supports the liquidity hypothesis and document a significant increase in the spread after removal after controlling for financial crisis impact. Overall, the results report support that changes in liquidity can explain the negative abnormal returns. These findings contribute the theoretical debate regarding the liquidity effects associated with changes in the composition of the FTSE 100 index.
\end{abstract}

Keywords: Liquidity effects, FTSE 100, Index changes, trading volume

*Corresponding author

1. Introduction 
This study investigates liquidity changes associated with removal of companies of from the FTSE 100 index. Stock market play significant role in financing firms of different size (Rossi, 2014; Rossi et al. 2015). Extensive research has recognised a price effect that occurs when companies are added to or removed from an index. However, there are disagreements regarding what causes this price effect, which also has implications for the permanency of the observed price effect (Denis, McConnell, Ovtchinnikov \& Yun, 2003; Erwin \& Miller, 1998; Harris \& Gurel, 1986; Jain, 1987; Shleifer, 1986). The liquidity hypothesis expects a permanent increase (decrease) in trading volume and a decrease (increase) in a stocks' bid/ask spread after addition (deletion) of a company that would result in permanent abnormal returns. The reason for this assumption is that transaction costs should be reduced after a company is added to the index due to increased attention to the stock from analysts and investors. The reduced information costs make the stocks more attractive to investors and thus increases the liquidity of the stock (Beneish \& Whaley, 1996). Afi (2017) reports that the disposition proxy is associated with lower returns, less volatility and smaller trading volume at the stock level.

However, Mase (2007) argue that this should not be the case with the FTSE 100 index because the revisions of the index are strictly rule-based and companies are ranked after market capitalization. Thus, another version of the liquidity hypothesis explains changes in liquidity with a reduction in transaction costs that is not triggered by any new information. Rather, added stocks become more attractive for investors when they are included, which reduces trading costs because there are more buyers and sellers for these stocks. This can for example be explained by passive index trackers or also by an increase in the amount of analysts following the stocks. The difference is that these analysts do not reveal that much new information, but are still able to trigger an increased demand.

In contrast, Beneish and Whaley (1996) rejects the liquidity hypothesis when studying the S\&P 500 index. They observe that the decrease in bid/ask spread only lasts one 
day after a company is added. Erwin and Miller (1998) and Hegde and McDermott (2003), on the other side, reject this finding and document that this decrease is permanent. Research undertaken on the FTSE 100 index is also contradicting. Gregouriou and Ionnaidis (2006) document that added companies experience a decrease in their bid/ask spread for added companies and an increase for deleted companies. This finding is supported by Mase (2007) who also document increased liquidity which he attributes to the non-information liquidity hypothesis. However, Gregoriou and Nguyen (2010) find no significant changes for removed companies which they argue is due to the London Stock Exchange electronic trading system. This is consistent with the findings of Mazouz and Saadoni (2007a) as they also did not find any differences in liquidity before and after companies were removed.

Our study examines the liquidity effects associated with removal of companies from the FTSE 100 index during the time period 2008-2016.The revisions made to the FTSE 100 index contain less information value because it makes its changes based on market capitalization and changes are therefore more transparent than those made to the S\&P 500 index (Mase, 2007). In addition, less research has been made on this index and the research that has been done document different results regarding changes in liquidity in the time around revisions (Gregoriou \& Loannidis, 2006; Gregoriou \& Nguyen, 2010; Mase, 2007; Mase, 2006; Mazouz and Saadouni, 2007a; Mazouz and Saadouni, 2007b). Our sample of deleted companies includes the years of the financial crisis. Thus, we also investigate the impact of the financial crisis on the liquidity of the removed companies from FTSE 100 index and whether the deleted companies in the years 2008-2009 experience a significant different increase in their bid-ask spread compare to those removed during the years 2010-2016.

Using a sample consisting of 67 removed companies from the FTSE 100 index from 2008-2016, the results report a decrease in removed companies' trading volume and a significant increase in the companies' bid/ask spreads lasting at least 30 days after removal. 
Our additional analysis shows that the deleted companies are more liquid during the financial crisis. However, the results also indicate that there are no significant differences between companies removed during the financial crisis and companies removed in the period after the financial crisis. Therefore, these results are consistent with the liquidity hypothesis as an explanation for the documented permanent negative abnormal returns. These findings are consistent with the arguments of the non-information liquidity hypothesis (Amihud; 1986; Mazouz \& Saadouni; 2007a).

These findings contribute to the literature by provide evidence on changes in liquidity associated with removal of companies from the FTSE 100 index during the time period 20082016. While most of the research has mainly focused on the additions of firms, the evidence reported for deleted companies are somewhat contradicting (Chen, Noronha \& Singal, 2004, Elliott et. al., 2006; Gregoriou and Ioannidis, 2006; Hegde \& McDermott, 2003; Kamal, Lawrence, McCabe \& Prakash, 2012; Kamal, 2014). For instance, Lynch and Mendenhall (1997) and Kamal (2014) document negative abnormal returns for deleted companies that revert to pre-announcement levels shortly after removal, where Chen et. al. (2004) and Elliot et. al. (2006) find no effect on deleted companies at all.

The remainder of the article is structured as follows. Section two reviews existing literature and presents the research hypotheses. The data sample and methodology is explained in section three. Findings and interpretations are then presented in section four. Finally, the conclusion summarizes the main points of this article in section five.

\section{Literature Review and Hypotheses}

\subsection{Previous Research}


Several factors affect stock liquidity; for instance, Demos and Marston (2010) indicate that visibility should result in better stock liquidity and increased stock price. Boujelbene, Bouri and, Prigent (2011) find that ownership effect depends on the owner identity and suggest that while state ownership is negatively related to spread, and positively related to market depth, foreign ownership has no significant effect on liquidity measures. Using a sample from India, Prasanna and Menon (2012) reveal that corporate governance had a positive impact on stock liquidity; also, better governed companies had higher liquidity. Hakim, Triki and, Omri (2008) find that earnings quality as a measure of the quality of financial reporting is associated negatively with bid-ask spreads and adverse selection spread components and thereby with a higher level of liquidity.

Extensive research, mostly conducted on the S\&P 500 index, has documented a price effect that occurs when a company is included to or removed from the index (Beneish \& Whaley, 1996; Chen et. al., 2004; Denis et. al., 2003; Erwin \& Miller, 1998; Kamal et. al., 2012; Kaul, Mehrotra \& Morck; 2000; Shleifer, 1986). This event causes abnormal returns that are positive for added companies and negative for removed companies. The observed price effect has then been tested on other indexes where the same abnormal returns are reported. Research provides mainly five different explanations for this effect; the downward sloping demand curve hypothesis, the price pressure hypothesis, the information hypothesis, the investor awareness hypothesis and the liquidity hypothesis (Denis et. al., 2003; Erwin \& Miller, 1998; Harris \& Gurel, 1986; Jain, 1987; Shleifer, 1986).

The downward sloping demand curve hypothesis explains positive abnormal returns due to an outward shift of the demand curve for an added company's stocks that should result in permanent positive abnormal returns. The explanation for the outward shift is that there is an increased demand after the added stock that is not triggered by any positive information. Shleifer (1986) is the first to support this hypothesis when he found such permanent positive 
abnormal returns following additions to the S\&P 500 index that also have a positive relationship with the growth the passive indexing. The reported results were then confirmed by Beneish and Whaley (1996) and Morck and Yang (2001). However, this hypothesis requires that there is no information content or signalling effect related with the revision of the index. Thus, Kaul, Mehrotra and Morck (2000) use the TSE 300 index to support those of Shleifer (1986) and reject the price pressure hypothesis ${ }^{1}$. Mazouz and Saadouni (2007a) also document permanent abnormal returns on the FTSE 100 index when taking account for the ARCH effect and allowing SIM parameters to vary systematically over time. According to Rossi et al. (2017) and Rossi (2015), there is no systematic evidence that corporate venture capital investments create value for the investing firms. Singh, Mehta and Hoolani (2010) study the price and volume effects of the addition to the index in Spain and conclude that the market reacts positively, to news of additions to the index and trading volumes exhibit commensurate significant changes. Their results imply the price effects may result largely from the demand-supply disequilibrium caused by index, rather than any new information or certification signalled by index inclusion (Singh, Mehta and Hoolani 2010)

However, Harris and Gurel (1986) found that the observed price effect on S\&P 500 is not permanent and thus support the price pressure hypothesis. This explanation assumes that the abnormal returns are compensations to investors for transaction costs and risk they carry when buying stocks that are added to the index or selling stocks deleted from it. Furthermore, the assumption is that the abnormal returns will go back to normal levels because then the demand will be perfectly elastic. Research that reports results consistent with this hypothesis are found by Lynch and Mendenhall (1997) from the S\&P 500, Biktimirov, Cowan and Jordan

\footnotetext{
${ }^{1}$ They argue that this event is a unique event because it was free from information effects, and therefore isolate price pressure effects.
} 
(2004) from the Russell 200 index and by Mase (2007) and Mazouz and Saadouni (2007b) from the FTSE 100 index.

In contrast, Jain (1986) rejected both the downward sloping demand curve hypothesis and the price pressure hypothesis. He argues that changes made to the index composition of S\&P 500 contain information to investors which make them change their perceptions of the added or deleted stocks. The information hypothesis is also confirmed by Dhillon and Johnson (1991) when they find that stock, bond and call prices increase after a company is included to the index, while put prices decrease. Denis et. al. (2003) and Wang, Lee and Singh (2013) find that forecasted EPS improve and that there is an increase in analyst coverage after a company is included to the index, which is interpreted as evidence that the revision of the S\&P 500 index convey information content. However, they remark that even though the event is not information free, it is problematic to find out whether the abnormal returns are caused by downward sloping demand curves or due to signaling effects.

The investor awareness hypothesis explains the price increase as a result of an increase in the added companies' future cash flows caused by a pressure from investors and traders for the companies to perform more efficiently and make value-increasing decisions (Chen et. al., 2004; Denis et. al., 2003). Capasso, Gallucci and Rossi (2015) reveal that longevity has positive economic and financial performance effects. In particular, Capasso, Gallucci and Rossi (2015) report that the oldest firm outperform the youngest in the wine industry.

Another explanation for the increased future cash flows is that investors do not have perfect information and thus require a lower discount rate (Elliott, Ness, Walker \& Warr, 2006). Chen et. al. (2004) Chen et. al. (2004) and Elliott et. al. (2006) report evidence from S\&P 500 of an increase in monitoring by investors, reduction in information asymmetry, easier access to capital and reductions in shadow costs for companies added to the S\&P 500 index. Elliot et. al. 
(2006) also document that the number of shareholders increase after addition. Furthermore, Chen et. al. (2004) discover that the effect for deleted firms are close to non-existent. These findings are argued to be logical, because a firm added to the index might immediately be pressured to improve the stewardship of the company, whereas a deletion might not necessarily remove the firm's access to capital markets.

The last explanation, which is the explanation empirically examined in this study, is the liquidity hypothesis. The liquidity hypothesis assumes that the increase in prices and trading volume of the stocks included to an index is related to liquidity changes that occur when stocks are added. The explanation is that analysts and investors are expected to examine the stocks more closely, which uncover more information regarding the companies and thus leads to increased trading and more liquid stocks (Beneish \& Whaley, 1996). The increased monitoring should lead to a bigger flow of information regarding the stocks and thus reduce information costs. If this is the case, there should be a permanent increase in trading volume and a permanent decrease in the bid/ask spread (Stoll, 1978). Another version of this hypothesis is the noninformation liquidity hypothesis, which explains positive abnormal returns and lower bid/ask spreads because of a reduction in inventory costs of market makers and thus a reduction in overall transaction costs (Amihud, 1986). In this case, excess demand for an added stock occurs even when there is no new information.

Beneish and Whaley's (1996) findings reject the liquidity hypothesis when using S\&P 500 as their index. They measure trading activity by looking at trading volume, trade size and bid/ask spreads. They find a significant increase in trading volume that is still significant after 60 days. However, even though they find a decrease in the bid/ask spread on the day following the day of stock addition, the decrease only lasts that one day. However, Beneish and Whaley's (1996) rejection of the liquidity hypothesis is challenged by the findings of Erwin and Miller (1998) and Hegde and McDermott (2003). Both document a permanent decrease in absolute 
and relative bid/ask spreads, after controlling for changes in share price, trading volume and return variance. Furthermore, Erwin and Miller (1998) find a permanent decrease in the bid/ask spreads for non-optioned stocks, that also experience a permanent increase in share price and trading volume. Both findings document changes in the stocks' liquidity after addition. However, they find no changes in the bid/ask spreads for optioned stocks and neither any permanent price increase. This finding is believed to be a result of arbitrage trading between the option and the underlying stock. Hegde and McDermott (2003) explain the improvement in liquidity with a documented significant decrease in the direct costs of trading and partly to a decrease in asymmetric information cost.

Gregoriou and Ioannidis (2006) looks further into the relationship between information costs and liquidity effects using the FTSE 100 index as their sample. They find that trading volume for increase and the bid/ask spread decrease for added companies. The opposite effect is found for companies removed from the index. Furthermore, they document a significant increase (decrease) in the number of analyst following added (removed) stocks, which they interpret as evidence for lower (higher) information costs that explains the liquidity hypothesis. Nevertheless, the opposite is claimed to be true by Kamal et. al. (2012) who argue that decreasing asymmetric information costs should lead to lower abnormal returns and marginal changes in liquidity associated with additions to the index. The decrease in the asymmetrical information costs are explained by changes and regulations implemented in the financial markets after year 2000, such as the Regulation Fair Disclosure, decimalization and the Sarbanes-Oxley Act (Kamal et. al., 2012). Their arguments are supported by the findings in their research, which document significantly lower abnormal returns and small changes in liquidity in the post-2000 period. These results are interpreted as lower information value in index composition changes. 
In a further study, Kamal (2014) examines deletions form the S\&P 500 index and finds that there is no difference in abnormal returns for the deleted stock for the pre-2000 period and the post-2000 period. However, the time it takes for the price reversion is shorter after year 2000. This is argued to be a result of a reduction in information asymmetry. Interestingly, the result shows a significant increase in bid/ask spreads in the post-2000 period which is interpreted as changes in liquidity. Still, the research contributes some evidence that the information environment has changed, which reduces observed price effect. Gregoriou and Nguyen (2010) also investigate deleted companies using the FTSE 100 index. They find no significant changes in liquidity after stocks are removed from the index. Furthermore, an argument is made that the London Stock Exchange electronic trading system guarantees that companies are still liquid after removal, and thus there is no statistical relationship between changes in investment opportunities and changes in stock liquidity.

\subsection{Hypotheses development}

As discussed above, while the literature on the topic is contradicting as to whether the abnormal returns are permanent and which hypothesis is the better explanation, more recent research have in common that they document decreasing asymmetry costs (Chen et. al, 2004, Elliott et. al., 2006; Gregoriou and Ioannidis, 2006; Hegde \& McDermott, 2003; Kamal et. al. 2012; Kamal, 2014). Furthermore, most of the research has mainly focused on additions of firms, and evidence reported for deleted companies are somewhat contradicting. Lynch and Mendenhall (1997) and Kamal (2014) document negative abnormal returns for deleted companies that revert to pre-announcement levels shortly after removal, where Chen et. al. (2004) and Elliot et. al. (2006) find no effect on deleted companies at all. Moreover, Mase (2007) report changes in liquidity that he assigns to the non-information liquidity hypothesis. Mazouz and Saadoni's (2007a) findings are consistent with Mase's interpretation when they document changes in liquidity for added companies. However, they find no significant 
differences in liquidity for deleted companies. Gregoriou and Nguyen (2010) agree with this observation and report that removed companies don't experience any changes in liquidity. Thus, this study will contribute to existing research by further investigate the effect on removed companies by using data from recent years over a long period of time.

We develop four hypotheses to test the relationship between negative abnormal returns and changes in liquidity. The liquidity hypothesis assumes that the price effect is caused by more investors trading in added stocks due to a more thoroughly examination of stocks added to the index. The opposite is the case for deleted stocks, where the logic is that they would not have the same appeal for the investors after removal, leading to less investors analysing them. These tendencies have implications for the abnormal returns, which can be argued to be a result of a price increase (decrease) experienced by added (deleted) companies due to lower (higher) information costs resulting in more (less) frequently trading. Even though empirical research present contradicting findings as to whether the deleted firms from the index experience the negative abnormal return that the liquidity hypothesis predicts, the hypothesis tested in this research will be based on the expectations of financial theory.

Hypothesis 1: There is a significant negative abnormal return after removal of a company from the FTSE 100 index.

The decrease of stock price after removal can be explained by an increased illiquidity of the removed stocks caused by less investor attention that increase trading costs associated with these stocks (Easly, Kiefer, O'Hara, \& Paperman, 1996). Thus, removed stocks is expected to experience an increased variability in trading over time and less trading in these stocks on average. Hence, the second hypothesis is that the trading volume of deleted stocks will go down.

Hypothesis 2: Deleted companies from the FTSE 100 index experience a permanent decrease in trading volume after removal. 
The reduction of number of investors analysing the removed stocks is expected to result in increased trading costs because the information costs of investing and/or the inventory costs of market makers increase. Simultaneously the risk of investing will also increase due to greater uncertainty of the company's position. The same negative relationship is also assumed to be true for the amount of traders in the market for a stock (Benston \& Hagerman, 1974). If there are many traders, this should reduce the bid/ask spread due to the competitive level. When there are few traders the bid and ask prices will be further apart since there is less competition pushing the prices closer to each other. Consequently, the natural progress is that a larger bid/ask spread arises for the deleted companies, as there is less information and demand after the company's stocks.

Hypothesis 3: Deleted companies from the FTSE 100 index experience a permanent increase in their bid/ask spread after deletion.

\section{Data and Methodology}

\subsection{Index Selection and Data Sample}

The data sample includes deleted companies from the FTSE 100 index from 2008 through 2016. The strength of this sample is that it contains recent data over a long period of time. The list of deleted companies is collected from FTSE' website (FTSE 100 Historic Additions and Deletions, 2017). FTSE 100 consists of UK's 100 biggest blue chip companies traded on the London Stock Exchange and is a weighted index based on market capitalization (FTSE, 2017). The index is rebalanced quarterly, where rebalancing occurs in March, June, September and December. In special cases rebalancing may occur in between these dates, if there is a need for a fast entry. The announcement of changes occurs on the Tuesday before the first Friday in March, June, September and December. These changes are then implemented 
after the market closes on the third Friday of the review month, making the effective day the following Monday.

The fact that the index' rebalancing is strictly rule-based and follows the ranking of companies according to their market capitalization argues in favour of that changes made here contain less new information than revisions of the S\&P 500 index (Mase, 2007). The S\&P 500 index is also updated quarterly and based on market capitalization. However, more subjectivity might be involved in the decision of changes as there is a committee that selects the components (S\&P Dow Jones Indices, 2017). Furthermore, this decision is also based on a company's liquidity, domicile, public float, sector classification, financial viability, length of time publicly traded and stock exchange. In this way, the changes to the S\&P 500 index is likely to convey more information compared to the FTSE 100 index.

There are in total 89 companies removed from FTSE 100 during 2008-2016. Six of these companies are removed from the sample because they are a result of acquisitions and mergers, which leaves a sample of 83 companies. The direction and magnitude of differences between the actual and expected return of a stock in listed companies involved in an M\&A could biased our results (Rossi, Tarba, and Raviv, 2013). Our study analyses abnormal returns, changes in trading volume and in bid/ask spreads and data is collected from DataStream. Companies without data available from the DataStream have been excluded, leaving final sample consists of 67 deleted companies from FTSE 100.

\subsection{Reseach Methodology}

\subsubsection{Abnormal Returns}

Our study employs the event study methodology to study the price effect (Brown \& Warner, 1985; Campbell \& Wasley, 1996; MacKinlay, 1997). Consistent with prior studies (Chen et. al., 2004; Kaul et. al, 2000; Lynch \& Mendenhall, 1997; Shankar \& Miller; 2006), 
the market adjusted return model is used to calculate the abnormal returns. Although existing research has used different approaches, Shankar and Miller (2006) calculate abnormal returns using different methods and notice that there is little difference in the results using any of the approaches. One of the advantages of the market adjusted return model is that it does not require an estimation period to calculate normal returns since the model calculates abnormal returns as the difference between the deleted stocks' returns and the return of the index (MacKinlay, 1997). This results in a bigger sample of companies because the price information for a few of the companies is unavailable in the year prior to the deletion date. The following formula for calculating abnormal returns:

$$
A R_{i, T}=R_{i, T}-R_{M, T}
$$

Where $A R_{i, T}$ is defined as the abnormal return for company $\mathrm{i}$ on event day $\mathrm{T}, R_{i, T}$ is the return of company $\mathrm{i}$ on event day $\mathrm{T}$ and $R_{M, T}$ is the return of the FTSE 100 index on event day T. Furthermore, the effective deletion date is defined as day 0 and abnormal returns are calculated in the event window of -12 days prior the deletion to +30 days after the removal. The average abnormal return for all removed companies is then calculated for each event date and compared to the average return of FTSE 100 on the all the sample dates in order to test for the significance.

Cumulative abnormal returns (CAR) are calculated using the formula

$$
C A R_{i}=\sum_{t=-12}^{30} A R_{i, T}
$$

Where the abnormal returns for each removed company in the event window $(-12,30)$ are summarised. To find the cumulative abnormal returns for all removed companies the same procedure as for the calculation of abnormal returns is followed. At last the cumulative average abnormal return (CAAR) is calculated using the formula 


$$
C A A R_{i}=\frac{1}{N} \sum_{-12}^{30} C A R_{i, T}
$$

Where the cumulative abnormal returns for company i on all event dates are summarized and divided on the total number of event days in the event window. Again, the same procedure as for the abnormal return is used to find the average CAAR for all removed companies in the sample.

\subsubsection{Abnormal volume}

To test for changes in liquidity around the event date, abnormal trading volume will be examined. With trading volume as a proxy for stock liquidity, a decrease in trading volume could explain a price effect when stocks are removed from the index. Similar to Lynch and Mendenhall (1997), Biktimirov, Cowan and Jordan (2004), Afi (2017), and Mase (2007), trading volume is calculated as follow:

$$
V_{i . T}=\alpha_{i}+\beta_{i} V_{M, T}+\epsilon_{i, T}
$$

Here, $V_{i, T}$ and $V_{M, T}$ are the trading volume of security $\mathrm{i}$ and the market index at time T. The parameters $\alpha_{i}$ and $\beta_{i}$ are found in an estimation window from -170 days until -18 days before the effective date of removal of the companies. It is assumed that the period prior to removal is the best standard for normal trading volume. After the parameters are determined, abnormal returns are calculated through the event window that is similar for the window used for the abnormal returns; from -12 days before removal to +30 days after.

\subsubsection{Changes in Bid/Ask Spread}

Another way to investigate whether changes in liquidity might contain an explanatory value to a price effect is to look at removed companies' bid/ask spreads. A panel data regression model is constructed to test for significant changes in the bid/ask spread of the deleted companies as follow. 


$$
\begin{aligned}
\frac{\text { Bid }_{\text {Ask }} \text { Spread }_{i t}}{} & =\alpha+\beta_{1} \text { PRICE }_{i t}+\beta_{2} \text { VOLUME }_{i t}+\beta_{3} \text { VARIANCE }_{i t} \\
& +\beta_{4} \text { POSTREMOVAL } \\
i t & +\beta_{5} F C+\text { YEAR effect }+\epsilon
\end{aligned}
$$

The bid/ask spread for deleted company $i$ on event day $t$ is the dependent variable and POST is the main variable of interest. The relative bid/ask spread is calculated by taking the absolute difference between the closing ask and bid prices, divided by the mid-point of the bid and ask prices (Mallouh and Tahtamouni, 2018; Hakim and Omri, 2009; Tasios and Bekiaris, 2014). Mallouh and Tahtamouni (2018) used the same proxy to the impact of the disclosure of corporate social responsibility on liquidity of the Jordanian industrial corporations. Likewise, Hakim and Omri, (2009) examines the association between bid-ask spread and auditor reputation. POST is a dummy variable to test for the difference of changes in bid/ask spreads that occurs after the company is removed, equal to 1 if time $t$ is post removal from the FTSE 100 and 0 otherwise.

Our model controls for a set of factors that influences the bid/ask spread (e.g. Hegde and McDermott 2003; Kaul, Mehrotra and Morck 2000; Erwin \& Miller, 1998; Copeland and Galai, 1983). We control for the changes in share price (PRICE), trading volume (VOLUME) and return variance (VARIANCE). Price is the closing share price of the deleted stock i on the same $\mathrm{t}$ as the bid and ask prices are collected. Trading volume is the total number of shares transacted during the day $\mathrm{t}$ for company $\mathrm{i}$. Variance is the estimated return variance which is calculated using the variance of stock returns the five days following day t. This regression will be run over a time interval that begins -12 event days before removal and ends +30 event days after. Since the data sample consists of companies removed during the financial crisis, this has also been included as a controlling variable (FC). 
4. Results and discussion

4.1 Abnormal Return (AR), Cumulative Abnormal Return (CAR) and Cumulative Average Abnormal Return (CAAR).

Two approaches are used to test whether the abnormal returns for the deleted companies are significant. The first test is a two-group comparison mean test that compares the abnormal returns between the removed companies 12 days before removal with the abnormal returns 12 day after their removal from the index. The second method to test for significance is a twosample comparison mean test, where the abnormal returns from the removed companies is compared with the return of the FTSE 100 index, separating the testing in a 12-day period prior to the removal and a testing window of 31 days beginning from effective day of removal. These two approaches are used both for testing abnormal returns, CAR and CAAR, and also for the testing for abnormal trading volume2. The results are reported in table 1.

Table 1: An analysis of AR, CAR and CAAR for removed companies

\begin{tabular}{|c|c|c|c|c|c|c|}
\hline & $\begin{array}{l}\text { Pre- Deletions } \\
(-12,-1) \text { vs. }\end{array}$ & $\begin{array}{c}\text { Post-Deletions } \\
(+1,+12)\end{array}$ & $\begin{array}{r}\text { Deletions } \\
(-1 \\
\end{array}$ & $\begin{array}{l}\text { FTSE } 100 \\
\text { 1) }\end{array}$ & $\begin{array}{l}\text { Deletions } \\
(0,+30)\end{array}$ & FTSE 100 \\
\hline AR & -0.011 & -0.006 & -0.011 & -0.001 & 0.003 & -0.005 \\
\hline$p$-value & 0.005 & & 0.000 & & 0.000 & \\
\hline CAR & -0.008 & -0.003 & -0.008 & -0.002 & 0.011 & -0.005 \\
\hline$p$-value & 0.333 & & 0.155 & & 0.000 & \\
\hline CAAR & -0.011 & -0.006 & -0.011 & -0.001 & 0.003 & -0.005 \\
\hline$p$-value & 0.010 & & 0.000 & & 0.000 & \\
\hline
\end{tabular}

Table (1) provide an analysis of AR, CAR and CAAR for removed companies. The sample is based on 67 deletions from FTSE 100. Abnormal returns, cumulative abnormal returns and cumulative average abnormal returns are calculated for each company for the event window $(-12,+30)$. The stock returns are then grouped into equally weighted portfolios for $A R, C A R$ and CAAR. A two-group comparison mean test is performed comparing abnormal returns in the 12-day period prior to removal with the 12-day period after removal. Two-comparison mean tests are done, comparing the deletions with the index in a 12-day period prior to removal and in 31-day period after the companies are removed beginning from the effective day.

\footnotetext{
${ }^{2}$ Our study uses also the nonparametric analysis to test group for differences in medians and all the results remain the same.
} 
The test shows a p-value of 0.005 for abnormal returns when comparing abnormal returns from the 12-day period prior to removal with the 12-day period after removal. This allows for a rejection of the null hypothesis at a significance level of $1 \%$ and confirms that there is a difference in abnormal returns before and after the companies are removed from the index. This suggests that abnormal returns are more negative in the period right before the companies are removed from the index. The statistical difference is also confirmed when comparing the abnormal returns of the removed companies with the return of the FTSE 100 index. The testing is done for a 12-day period prior to the removal, and for the 31 days following the effective day. Both in the 12-day period prior to removal and in the 30-day period after removal, companies experience a significant abnormal return that is more negative than experienced by the index in total.

Similar significant differences are reported from the results of CAR when comparing the removed companies with the index in the period after removal and for all of the CAAR tests. However, the observations are not significant for the CAARs when comparing the 12-day period prior to removal with the 12-day period after removal and when comparing the deleted companies with the index in the period prior to removal. Regardless, the main results document that removed companies experience negative abnormal returns that are significant in the majority of the tests. The validity of these results has been checked by testing the median of AR, CAR and CAAR using nonparametric Wilcoxon tests. The results are similar to those testing the mean difference and confirms the findings.

Previous research made on revisions of the FTSE 100 index have documented that added and deleted companies to the index experience abnormal returns caused by the revision of index. The results in this research support this finding. The performed comparison mean tests find that negative abnormal returns for removed companies are significant before and after the event. Furthermore, the tests document bigger negative abnormal returns prior to removal than 
after, with a daily average difference of $-0.5 \%$ during the 12 days before the companies are removed. The results show that the companies experience $1 \%$ more negative abnormal returns than the index as a daily average in the 12 days prior to removal. Even 30 days after removal the companies experience a significant negative abnormal return with a daily average through the period of $-0.5 \%$. This finding differs from that of Mazouz and Saadouni (2007b) that document complete reversal within two weeks after removal. However, the results support research that have documented a long-term price effect (Gregoriou and Ioannidis, 2006; Mase, 2006; Mazouz and Saadouni, 2007a) ${ }^{3}$. This finding rejects the price pressure hypothesis that claims that the abnormal returns will revert to normal shortly after the event. Furthermore, the documented effect that companies experience a bigger negative abnormal return in the 12-day period before removal compared with the 12-day period after removal is also consistent with previous research. Mase (2007) found increased trading prior to announcement of revisions and Mazouz and Saadouni (2007a) documented higher abnormal returns prior to the effective change date. The reason is argued to be the way the FTSE 100 index includes its constituents. As mentioned, the index includes the biggest blue-chip companies based on their market capitalization. Thus, it might be possible to predict which companies are going to be added and which companies are going to be removed before the announcement is made. Furthermore, in the period from announcement of removal to the effective date gives traders two weeks to respond to the announced changes before the changes are actual implemented.

\subsection{Abnormal Volume}

Abnormal volume (AV) is tested using the similar method as with the abnormal returns. These tests are made to see if there is a significantly decreased trading in the removed

\footnotetext{
${ }^{3} \mathrm{~A}$ long-term or permanent price effect is defined, in line with previous research, that abnormal returns are still significant after 30 days.
} 
companies' stocks which has implications for their liquidity. The results are reported in table 2.

Table (2) an analysis of AR, CAR and CAAR for removed companies AV for removed companies

\begin{tabular}{|c|c|c|c|c|c|c|}
\hline \multirow[b]{2}{*}{$\begin{array}{l}A V \\
p \text {-value }\end{array}$} & \multicolumn{2}{|c|}{$\begin{array}{c}\text { Deletions Prior Deletions Post } \\
(-12,-1) \text { vs. }(+1,+12)\end{array}$} & \multicolumn{2}{|c|}{$\begin{array}{c}\text { Deletions FTSE } 100 \\
(-12,-1)\end{array}$} & \multicolumn{2}{|c|}{$\begin{array}{l}\text { Deletions FTSE } 100 \\
(0,+30)\end{array}$} \\
\hline & $\begin{array}{l}0.816 \\
0.243\end{array}$ & 0.394 & 0.816 & -0.033 & $\begin{array}{l}0.269 \\
0.000\end{array}$ & 0.007 \\
\hline
\end{tabular}

Table (2) an analysis of AR, CAR and CAAR for removed companies AV for removed companies. The sample is based on 67 deletions from FTSE 100. Abnormal volume is calculated for each company for the event window $(-12,+30)$. The estimation of parameters is calculated using linear regression on the removed companies' daily trading volume for the estimation window $(-170,-18)$. The companies are then grouped into equally weighted portfolios. A two-group comparison mean test is performed comparing abnormal volume in the 12-day period prior to removal with the 12-day period after removal. Twocomparison mean tests are done, comparing the deletions with the index in a 12-day period prior to removal and in 31-day period after the companies are removed beginning from the effective day.

When comparing the deletions in the 12-day interval prior to removal with the 12-day interval after removal, the mean trading volumes show that the stocks experience an average decrease in volume after they are removed. However, this result is not significant and the null hypothesis cannot be rejected. The other comparison mean test, on the other hand, give significant results that confirm that the companies experience different trading volumes compared to the index. More specific, the companies experience higher trading volumes than the index in general. More importantly, they also experience a decrease in trading volume after they are removed, which is consistent with the liquidity hypothesis. This finding is consistent with those of Mase (2007) and Mazouz and Saadouni (2007a), who document that trading volume is at its highest right before the changes are made. Gregoriou and Ioannidis (2006), however, document that volume decreases for deleted firms when testing on the fifth trading day after the announcement is made. Still, the results are consistent the explanation of Mase (2007) and Mazouz and Saadouni (2007a) that index fund trackers adjust their portfolios in the period before changes are made. 


\subsection{Changes in the Relative Bid/Ask Spread}

Consistent with Rokhmawati, Gunardi and Rossi (2017), Changes in bid/ask spreads are tested running a linear regression model. The main variable of interest is the dummy variable for time (POST) because this will clarify whether there are significant changes in the bid/ask spreads for the companies before and after they are removed. The regression is run while controlling for price, volume, variance and the separation of companies removed during the financial crisis. Dummy variables are also constructed for each year to investigate the differences over time. The results are reported in table 3.

Table 3: Regression analysis for changes in bid/ask spread of removed companies from FTSE 100

\begin{tabular}{|l|lc|}
\hline Relative Ask bid Spread & Coef. & t-value \\
\hline POST & $0.001^{* * *}$ & 2.66 \\
PRICE & 0.003 & 1.15 \\
VARIANCE & 0.006 & 1.11 \\
VOLUME & $-0.002^{* *}$ & -2.19 \\
FC & $-0.001^{* *}$ & -2.13 \\
Cons & $-8.014^{* * *}$ & 4.9823 \\
\hline N.of observation & 4078 & \\
adj. R-sq & 0.0412 & \\
Time Effect & Yes & \\
Firm Clustered SE & Yes & \\
\hline
\end{tabular}

Table (3) presents the regression analysis for changes in bid/ask spread using sample of 67 deleted companies during 20082016. This regression will be run over a time interval that begins -12 event days before removal and ends +30 event days after. The model as follow

Relative Spread $_{i t}=\alpha+\beta_{1}$ PRICE $_{i t}+\beta_{2}$ VOLUME $_{i t}+\beta_{3}$ VARIANCE $_{i t}+\beta_{4}$ POST $_{i t}+\beta_{5}$ FC + YEAReffect $+\epsilon$ Variables definitions:

The relative bid/ask spread is calculated by taking the absolute difference between the closing ask and bid prices, divided by the mid-point of the bid and ask prices. POST is a dummy variable to test for the difference of changes in bid/ask spreads that occurs after the company is removed, equal to 1 if time $\mathrm{t}$ is post removal from the FTSE 100 and 0 otherwise. PRICE is the closing share price of the deleted stock $i$ on the same $t$ as the bid and ask prices are collected. VOLUME is the total number of shares transacted during the day $t$ for company $i$. VARIANCE is the estimated return variance which is calculated using the variance of stock returns the five days following day $t$. FC is a dummy variable coded 1 if the time is 2008 and 2009 and 0 otherwise.

The results show that after a company is removed the bid/ask spread increased compared to the 12-day period before the company removal, as the coefficient of POST is positive and 
significant $(\beta=.001 * * *)$. This finding is consistent with the hypothesis that the companies experience an increase in their bid/ask spreads after removal.

The observed changes in the bid/ask spread support the liquidity explanation and are also consistent with the reduced liquidity found in the tests for abnormal volume. It is documented that the bid/ask spreads significantly increase after the companies are removed from the index. This finding is contradicting Gregoriou and Nguyen (2010) that found no changes in liquidity after deletions on the FTSE 100 index and Mazouz and Saadouni (2007a) who only found that changes in the bid/ask spreads were significant for added companies. However, Gregory and Loannidis (2006) also found permanent decreased liquidity for deleted companies which they explained as a result of a documented reduction in the amount of investor analysts that followed the companies after they were removed. Mazouz and Saadouni (2007a) and Mase (2007) advocate the non-information liquidity hypothesis and argues that the changes in liquidity is not necessarily because of access to any new information. The explanation that deleted companies experience a decrease in the amount of investors following their stocks is a plausible explanation when considering the documented decrease in trading volume after removal. Less trading in a stock will increase the spread between the bid and ask prices as it has fewer buyers and sellers to push their prices closer together. The result thus imply that the removed companies' stocks become less attractive to invest in when they are not included in the index. The reduced liquidity might be explained by several reasons, for example a decrease in the amount of analysts following the stock or because there are a lot of index trackers that readjust their portfolios when announcement of change is made. Either way, the results in the two-sample comparison mean test for abnormal volume is consistent with the documented decreased liquidity in the bid/ask spreads. 


\section{Additional Analysis}

The sample of deleted companies includes the years of the financial crisis4. Thus, it is interesting to investigate whether companies removed from FTSE 100 index experience significant changes in their bid/ask spreads during the financial crisis (2008 and 2009) and whether the deleted companies from the FTSE 100 index in the years 2008-2009 experience a significant different changes in their bid-ask spread compare to those removed during the years 2010-2016. Scholes (2000) and Brown, Carlin and Lobo (2010) notice that during a financial crisis investors sell their most liquid assets due to an increased need of cash to meet their debt requirements, financing and the general uncertainty regarding the future. Following this logic, in the years of a financial crisis positive abnormal returns for added stocks should be lower, if not non-existent, because investors want to sell these stocks instead of buying them as they would in normal years. For the removed companies, the negative abnormal return should be even larger considering that the FTSE 100 includes the biggest companies in UK and in a crisis an even larger number of investors would want to sell their shares for the removed companies. On the other hand, Ben-David, Franzoni and Moussawi (2012) found that hedge fund investors liquidiated their holdings three times as much as mutual fund investors during years of financial distress. Furthermore, Apergis, Artikis and Kyriazis (2015) document that, during times of distress, investors tend to reallocate their portfolios from risky small-cap stocks to large-cap stocks with higher liquidity. This implies that the effect of the financial crisis on abnormal returns in these years, if caused by the liquidity hypothesis, might not be as severe. Thus, it is difficult to predict how the forces of the financial crisis will affect companies removed from the index during this period.

\footnotetext{
${ }^{4}$ The financial crisis is defined as the years 2008-2009.
} 
The result from the regression analysis in table 4 suggests that the financial crisis decreases the bid-ask spread for removed companies, as the coeffient of FC is negative and signficant $\left(\beta=.0014 * * *\right.$ and $\left..0013^{* *}\right)$. Thus, the deleted companies are more liquid during the financial crisis. To further investigate whether the deleted companies from the FTSE 100 index in the years 2008-2009 experience a significant different changes in their bid-ask spread compare to those removed during the years 2010-2016, an interaction term is added to the regression analysis. The interaction terms (POSTFC) linking the variables POST and financial crisis. However, the results show that there are no significant differences, suggesting that the impact financial crisis on liquididy has no effect on the main results.

Table 4: Regression analysis for the effect of financial crisis on bid/ask spread of removed companies from FTSE 100 during

\begin{tabular}{|l|c|c|}
\hline Relative Ask bid Spread & Coef. & Coef. \\
\hline POST & $0.001^{* * *}$ & $0.001^{* * *}$ \\
PRICE & 0.003 & 0.003 \\
VARIANCE & 0.006 & 0.006 \\
VOLUME & $-0.002^{* *}$ & $-0.001^{* *}$ \\
FC & $-0.0014^{* *}$ & $-0.0013^{* *}$ \\
POSTFC & & 0.0009 \\
Cons & $-8.014^{* * *}$ & 0.002 \\
\hline N.of observation & 4078 & 4078 \\
adj. R-sq & 0.0412 & 0.0048 \\
Time Effect & Yes & Yes \\
Firm Clustered SE & Yes & Yes \\
\hline
\end{tabular}

Table (4) presents Regression analysis for the effect of financial crisis on bid/ask spread of removed companies from FTSE 100 during. This regression will be run over a time interval that begins -12 event days before removal and ends +30 event days after. The model as follow

Relative Spread $_{i t}=\alpha+\beta_{1}$ PRICE $_{i t}+\beta_{2}$ VOLUME $_{i t}+\beta_{3}$ VARIANCE $_{i t}+\beta_{4}$ POST $_{i t}+\beta_{5} F C+\beta_{6}$ POSTFC YEAR effect $+\epsilon$

Variables definitions:

The relative bid/ask spread is calculated by taking the absolute difference between the closing ask and bid prices, divided by the mid-point of the bid and ask prices. POST is a dummy variable to test for the difference of changes in bid/ask spreads that occurs after the company is removed, equal to 1 if time $\mathrm{t}$ is post removal from the FTSE 100 and 0 otherwise. PRICE is the closing share price of the deleted stock $i$ on the same $t$ as the bid and ask prices are collected. VOLUME is the total number of shares transacted during the day $t$ for company $i$. VARIANCE is the estimated return variance which is calculated using the variance of stock returns the five days following day $t$. FC is a dummy variable coded 1 if the time is 2008 and 2009 and 0 otherwise. POSTFC is interaction term between POST and FC. 


\section{Conclusion}

This study investigates a documented price effect that occurs when companies are deleted from the FTSE 100 index. We examine whether changes in liquidity can explain the negative abnormal return companies experience after they are removed. The FTSE 100 index is chosen because there is less research conducted on this particular index and because it is argued that due to the nature of how the index chooses its constituents, revisions of the index should not contain any new information that can cause the abnormal returns. The sample consists of 67 removed companies during the period 2008-2016. The strengths of this sample are that it is over a long period of time and includes very recent figures compared with previous research.

This study follows an event study methodology defining the date of removal as the effective day and using a testing window that begins -12 event days before removal and ends +30 days after removal. To test for abnormal returns and abnormal volume, two-group comparison mean tests and two-sample comparison mean tests have been conducted. Using two different tests increases the validity of the results because differences are tested by comparing the removed companies against themselves before and after removal and by comparing the companies to the index itself. The relative bid/ask spreads are used as a measure of changes in liquidity and is tested by running pooled regression with relative bid/ask spread as dependent variable while controlling for price, volume and return variance and financial crisis.

Our findings confirm that removed companies from the index experience negative abnormal returns that are still significant 30 event days after removal. Furthermore, the negative abnormal returns are more negative in the 12-day period prior to removal compared to the 12 day and 30-day period after removal. This finding is consistent with previous research that document that the day of the greatest abnormal returns is one day before the effective date. Results reported from trading volume and bid/ask spreads support the liquidity hypothesis as 
an explanation for the negative abnormal returns. The tests for abnormal volume show that removed companies' stocks experience a decrease in trading volume after the companies are removed, which is interpreted as a decrease in these stocks' liquidity. The relative bid/ask spread confirms the hypothesis that the removed companies experience an increase in their bid/ask spreads after removal and is consistent with the results reported for abnormal volume even during the financial crisis. The interpretation is that removed companies become less liquid after their removal, where plausible explanations for this might be that the amount of investor analysts following their stocks reduces when the companies are removed and that there is a large amount of passive index trackers that remove the companies from their portfolios and funds when they are removed from the index. In this way, the liquidity hypothesis might at least partly explain the negative abnormal returns. Furthermore, the additional analysis suggests that the financial crisis decreases the bid-ask spread for removed companies. However, the main results remain the same after controlling for the impact financial crisis on the liquidly. In other words, there was no significant difference between the companies removed during period 20082009 and those removed during 2010-2016. In this study, the market adjusted return model is used to calculate the abnormal returns. However, other measures may be used such as estimating the parameters for normal return in an event window either prior to or after the effective date or a nonparametric model where the difference between the stocks' returns and the market return, usually defined as the index, is calculated (Chen et. al., 2004). Shankar and Miller (2006) calculate abnormal returns using all the three above mentioned methods and notice that there is little difference in the results using any of the approaches. Nevertheless, future research may used other proxies to explore the same issue. 


\section{References}

Afi, H. (2017). An examination of the relationship between the disposition effect and stock return, volatility, and trading volume: the evidence in US stock markets. International Journal of Managerial and Financial Accounting, 9(3), 242-262.

Aliani, Khaoula, Imen Mhamid, and Matteo Rossi. "Does CEO overconfidence influence tax planning? Evidence from Tunisian context." International Journal of Managerial and Financial Accounting 8.3-4 (2016): 197-208.

Amihud, Y. (1986). Asset pricing and the bid-ask spread. Journal of Financial Economics, $17(2), 223-249$.

Apergis, N., Artikis, P. G. \& Kyriazis, D. (2015). Does stock market liquidity explain real economic activity? New evidence from two large European stock markets. Journal of International Financial Markets, Institutions \& Money, 38, 42-64.

Ben-David, I., Franzoni, F. \& Moussawi, R. (2012). Hedge fund stock trading in the financial crisis of 2007-2009. The Journal of Finance, 68(6), 2383-2434.

Beneish, M. \& Whaley, R. (1996). An anatomy of the "S\&P game": the effects of changing the rules. Journal of Finance, 51(5), 1909-1930.

Benston, G. J. \& Hagerman, R. L. (1974). Determinants of bid-asked spreads in the over-thecounter market. Journal of Financial Economics, 1, 353-364.

Biktimirov, E., Cowan, A. \& Jordan, B. (2004). Do demand curves for small stocks slope down? The Journal of Financial Research, 27(2), 161-178.

Boujelbene, N. B., Bouri, A., \& Prigent, J. L. (2011). Ownership structure and stock market liquidity: evidence from Tunisia. International Journal of Managerial and Financial Accounting, 3(1), 91-109.

Brown, D. B., Carlin, B. I. \& Lobo, M. S. (2010). Optimal portfolio liquidation with distress risk. Management Science, 56(11), 1997-2014.

Brown, S. J. \& Warner, J. B. (1985). Using daily stock returns; the case of event studies. Journal of Financial Economics, 14(1), 3-31. 
Campbell, B. P. \& Wasley, C. E. (1996). Measuring daily trading volume for samples of NYSE/ASE and NASDAQ securities using parametric and nonparametric test statistics. Review of Quantitative Finance and Accounting, 6, 209-326.

Chen, H., Noronha, G. \& Singal, V. (2004). The price response to S\&P index additions and deletions: evidence of asymmetry and a new explanation. Journal of Finance, 59(4), 19011929.

Copeland, T., \& Galai, D. (1983). Information Effects on the Bid-Ask Spread. The Journal of Finance, 38(5), 1457-1469. doi:10.2307/2327580

Demos, N., \& Marston, C. (2010). Firm visibility via group presentations. International Journal of Managerial and Financial Accounting, 2(1), 63-94.

Denis, D., McConnell, J., Ovtchinnikov, A. \& Yun, Y. (2003). S\&P 500 index additions and earnings expectations. Journal of Finance, 58(5), 1821-1840.

Dhillon, U. \& Johnson, H. (1991). Changes in the Standard and Poor's list. Journal of Business, 1, 75-85.

Easley, D., Kiefer, N.M, O’Hara, M. \& Paperman, J. B. (1996). Liquidity, information, and infrequently traded stocks. The journal of finance, 51(4), 1505-1436.

Elliott, W. B., Ness, B. F., Walker, M. D. \& Warr, R. S. (2006). What drives the S\&P 500 inclusion effect? An analytical survey. Financial Management, 35(4), 31-48.

Erwin, G. R. \& Miller, J. M. (1998). The liquidity effects associated with addition of a stock to the S\&P 500 index; evidence from the bid/ask spreads. Financial Review, 33(1), 131-146.

FTSE. (2017, June). FTSE 100 Historic Additions and Deletions. Retrieved from www.ftse.com: http://www.ftse.com/products/downloads/FTSE 100 Constituent history.pdf

FTSE. (2017, June 30). FTSE 100 index. Retrieved from www.ftse.com:

http://www.ftse.com/Analytics/FactSheets/temp/2f44af0a-362c-415a-9a11-958b60a28247.pdf

Galati, A., Crescimanno, M., Rossi, M., Farruggia, D., \& Tinervia, S. (2014). The determinants affecting the internationalisation of the Italian SMEs producing sparkling wines: an empirical study on the RBV of the firms. International Journal of Globalisation and Small Business, 6(2), 100-118. 
Gregoriou, A. \& Ioannidis, C. (2006). Information costs and liquidity effects from changes in the FTSE 100 list. European Journal of Finance, 12, 347-360.

Gregoriou, A. \& Nguyen, N. D. (2010). Stock liquidity and investment opportunities: new evidence from FTSE 100 index deletions. Journal of International Financial Markets, Institutions \& Money, 20, 267-274.

Hakim, F., \& Omri, A. (2009). Does auditor reputation reduce information asymmetry? Evidence from Tunisia. International Journal of Managerial and Financial Accounting, 1(3), 235-247.

Hakim, F., Triki, F., \& Omri, A. (2008). Earnings quality and equity liquidity: evidence from Tunisia. International Journal of Managerial and Financial Accounting, 1(2), 147-165.

Harris, L. \& Gurel, E. (1986). Price and volume effects associated with changes in the S\&P 500 list: new evidence for the existence of price pressures. Journal of Finance, 41(4), 815829.

Hegde, S. P. \& McDermott, J. B. (2003). The liquidity effects of revisions to the S\&P 500 index; an empirical analysis. Journal of Financial Markets, 6(3), 413-459.

Jain, P. (1987). The effect on stock price of inclusion or exclusion from the S\&P 500. Financial Analyst Journal, 43(1), 58-65.

Kamal, R. (2014). New evidence from S\&P 500 deletions. International Journal of Business and Finance Research, 8(2), 1-10.

Kamal, R., Lawrence, E. R., McGabe, G \& Prakash, A. J. (2012). Additions to S\&P 500 index: not so informative anymore. Managerial Finance, 38(4), 380-402.

Kaul, A., Mehrotra, V. \& Morck, R. (2000). Demand curves for stocks do slope down; new evidence from an index weights adjustment. Journal of Finance, 55(2), 893-912.

Lynch, A. \& Mendenhall, R. (1997). New evidence on stock price effects associated with changes in the S\&P 500 index. Journal of Business, 70(3), 351-383.

MacKinlay, A. C. (1997). Event studies in economics and finance. Journal of Economic Literature, 35(1), 13-39. 
Mallouh, A. A., \& Tahtamouni, A. (2018). The impact of social responsibility disclosure on the liquidity of the Jordanian industrial corporations. International Journal of Managerial and Financial Accounting, 10(3), 273-300.

Mase, B. (2007). The impact of changes in the FTSE 100 index. Financial Review, 42(3), 461-484.

Mazouz, K. \& Saadouni, B. (2007a). New evidence on the price and liquidity effects on the FTSE 100 index revisions. International Review of Financial Analysis, 16(3), 223-241.

Mazouz, K. \& Saadouni, B. (2007b). The price effects of FTSE 100 index revision: what drives the long-term abnormal return reversal? Applied Financial Economics, 17(6), 501-510. Morck, R. \& Yang, F. (2001). The mysterious growing value of S\&P 500 membership. (NBER working paper No. 8564). Cambridge: National Bureau of Economic Research.

Prasanna, P. K., \& Menon, A. S. (2012). Corporate governance and stock market liquidity in India. International Journal of Behavioural Accounting and Finance, 3(1-2), 24-45.

Rokhmawati, A., Gunardi, A., \& Rossi, M. (2017). How powerful is your customers' reaction to carbon performance? Linking carbon and firm financial performance. International Journal of Energy Economics and Policy, 7(6), 85-95.

Rossi, M. (2015). The role of venture capital funds in financing innovation in Italy. Constraints and challenges for innovative small firms. International Journal of Globalisation and Small Business, 7(2), 162-180.

Rossi, M. (2014). Capital structure of small and medium enterprises: the Italian case. International Journal of Globalisation and Small Business 6.2 130-144.

Rossi, M., Lombardi, R., Nappo, F., \& Trequattrini, R. (2015). The capital structure choices of agro-food firms: evidence from Italian SMEs. International Journal of Management Practice, 8(3), 172-186.

Rossi, Matteo, Shlomo Yedidia Tarba, and Amos Raviv.(2013) "Mergers and acquisitions in the hightech industry: a literature review." International Journal of Organizational Analysis 21: 66-82.

Rossi, M., Festa, G., Solima, L., \& Popa, S. (2017). Financing knowledge-intensive enterprises: evidence from CVCs in the US. The Journal of Technology Transfer, 42(2), 338-353. 
S\&P Dow Jones Indices. (2017, April). S\&P U.S. indices methodology. Retrieved from www.us.spindices.com: http://us.spindices.com/documents/methodologies/methodology-sp$\underline{\text { us-indices.pdf }}$

Scholes, M. S. (2000). The near crash of 1998. American Economic Review, 90, 17-21.

Shleifer, A. (1986). Do demand curves for stocks slope down? Journal of Finance, 41(3), 579590.

Singh, T., Mehta, S., \& Hoolani, U. (2010). The effects of index changes in the Spain Stock Market. International Journal of Managerial and Financial Accounting, 2(3), 305-325.

Stoll, H. R. (1978). The supply of dealer services in securities markets. Journal of Finance, 33(4), 1133-1151.

Tasios, S., \& Bekiaris, M. (2014). Mandatory disclosures and firm characteristics: Evidence from the Athens stock exchange. International Journal of Managerial and Financial Accounting, 6(4), 303-321.

Wang, Q., Lee, W. \& Singh, V. (2013). S\&P 500 index revisions and analyst coverage. The journal of Applied Business Research, 29(4), 1199-1207. 